\title{
PROPOSTA PEDAGÓGICA PARA A AVALIAÇÃO POR PARES EM ATIVIDADES DE EXECUÇÃO MUSICAL: PRIMEIRAS AÇÕES
}

Daniel Mill ${ }^{1}$

Glauber Lúcio Alves Santiago ${ }^{2}$

José Alessandro Gonçalves²

Isamara Alves Carvalho ${ }^{2}$

\section{RESUMO}

Este artigo apresenta os primeiros passos de um estudo realizado por dois grupos de pesquisa, um na área de música e outro na área de educação. Trata-se de um projeto de longa duração com desdobramentos e diversos outros projetos de pesquisa subsidiários. 0 objetivo desse projeto maior é, por meio da abordagem chamada Design-Based Research $(D B R)$, descobrir quais são as características de um sistema de avaliação por pares, para gerar aprendizagem dos estudantes e satisfação dos docentes em disciplinas de execução musical em cursos de graduação em música. O projeto aborda uma fundamentação teórica, aplicação e funcionamento geral da $D B R$, apresenta o objeto de estudo geral que é avaliação em cursos superiores de música e posteriormente a avaliação por pares. A partir daí o artigo traz a dinâmica de trabalhos realizada e os diversos subprojetos que estão sendo desenvolvidos e previstos para as primeiras fases da $D B R$.

Palavras-chave: Avaliação por pares. Design-based research. Avaliação da execução musical.

\footnotetext{
${ }^{1}$ Departamento de Educação, Universidade Federal de São Carlos, São Carlos, SP, Brasil.

${ }^{2}$ Departamento de Artes e Comunicação, Universidade Federal de São Carlos, São Carlos, SP, Brasil.
} 


\section{PEDAGOGICAL PROPOSAL FOR THE PEER EVALUATION IN MUSICAL EXECUTION ACTIVITIES: FIRST ACTIONS}

Daniel Mill

Glauber Lúcio Alves Santiago

José Alessandro Gonçalves

Isamara Alves Carvalho

\section{ABSTRACT}

This article presents the first steps of a research conducted by two research groups, one in the area of music and another in the area of education. This is a long-lasting project with deployment and several other subsidiary research projects. The objective of this larger project is, through the approach called Design-Based Research (DBR), to discover what are the characteristics of a system of peer evaluation to generate student learning and teacher satisfaction in music performance disciplines in music undergraduate courses. This article addresses a theoretical foundation, application and general functioning of the DBR and then presents the object of general study that is evaluation in higher courses of music and then the peer evaluation. From this, the article presents the dynamics of the work carried out and the various subprojects being developed and planned for the first phases of the DBR.

Keywords: Peer evaluation. Design-based research. Musical performance assesment. 


\section{INTRODUÇÃO}

A área de música da Universidade Federal de São Carlos (UFSCar) é recente e apenas há poucos anos vários professores se doutoraram. Porém, a área ainda enfrenta desafios para se destacar na pesquisa e poder, inclusive, pensar em abrir um programa de pós-graduação. Nesse sentido, dois grupos de pesquisa ${ }^{3}$ iniciaram o estudo e a utilização de uma abordagem metodológica que alia três necessidades urgentes da área da música na Universidade: fortalecimento das pesquisas em grupo; realização de pesquisas que resultem, além de desenvolvimento teórico, em benefícios para a práxis do ensino superior em música; e criação de uma rotina de pesquisa no dia a dia dos diversos docentes desse grupo. Sendo assim, vários projetos de pesquisa periféricos têm sido propostos na órbita de um projeto geral intitulado $O$ design de propostas pedagógicas envolvendo a avaliação por pares em atividades de execução musical.

\section{A Design-Based Research}

Ensino, pesquisa e extensão construídos na interface música e educação é uma vocação de um grupo específico de professores e pesquisadores da UFSCar, que conta com diversos projetos de extensão voltados para a educação musical, além de possuir dois cursos de licenciatura, sendo um presencial e outro na modalidade a distância. Nesse contexto, o grupo da música deseja focar-se em pesquisas educacionais, e assim surge a primeira pergunta: qual o objetivo da pesquisa educacional? Nesse sentido, autores como Plomp e Nieveen comentam que

$$
\begin{aligned}
& \text { [...] o foco em toda pesquisa científica é a busca pelo "entendimento" } \\
& \text { ou pelo "conhecimento" com o objetivo que contribuir para o corpo } \\
& \text { de conhecimento e teoria no domínio da pesquisa. Outro objetivo } \\
& \text { geral da pesquisa educacional é fornecer reflexões e contribuições } \\
& \text { para a prática, e para fundamentar tomadas de decisão e políticas de } \\
& \text { desenvolvimento na área da educação (PLOMP; NIEVEEN, 2007, p. 10, } \\
& \text { tradução nossa). }
\end{aligned}
$$

Nesse mesmo sentido, tem-se a contribuição de um grupo internacional de pesquisadores chamado Design-Based Research Collective. Para esse grupo,

\footnotetext{
${ }^{3}$ Grupos: 1) Tecnologias Aplicadas à Criação, à Expressão e ao Ensino Musicais e 2) Grupo de Estudos e Pesquisas sobre Inovação em Educação, Tecnologias e Linguagens.
} 
[...] pesquisadores educacionais, legisladores e profissionais concordam que a pesquisa educacional está, frequentemente, divorciada dos problemas e questões da prática cotidiana uma separação que cria a necessidade de novas abordagens de pesquisa que dialoguem diretamente com os problemas práticos (DESIGN-BASED RESEARCH COLLECTIVE, 2003, p. 5, tradução nossa).

Considerando, então, essa dupla faceta da pesquisa na educação, que é aliar resultados cientificamente embasados com resultados úteis para o aprimoramento da prática educativa, foi desenvolvida, entre as décadas de 1990 e 2000, a abordagem comumente chamada de design-based research. Ela é inovadora e não se confunde com outras abordagens ou metodologias, como a pesquisa experimental de laboratório, o design, a pesquisa ação e a avaliação formativa. Porém, existem vários termos utilizados para designar a design-based research, como indicam Van Den Akker et al. (2006, p. 4): “Design research, Design studies, Design experiments, Development/Developmental research, Formative research, Formative evaluation, Engineering research". Matta et al. (2014) defendem o uso do termo em português "Pesquisa de Desenvolvimento". Porém, neste projeto manteremos o termo em inglês, por ser de uso mais comum na literatura científica em português. A seguir são traçadas algumas definições sobre a abordagem.

A pesquisa educacional por projetos (educational design research), que é como muitos pesquisadores se referem à $D B R$,

[...] é percebida como o estudo sistemático do projeto, desenvolvimento e avaliação de intervenções educacionais (tais como programas, estratégias e materiais de ensino-aprendizagem, produtos e sistemas), assim como as soluções para problemas educacionais que resultem no avanço do nosso conhecimento sobre as características destas intervenções e dos seus processos de projeto e intervenção (PLOMP; NIEVEEN, 2007, p. 9, tradução nossa).

Dessa definição pode-se destacar os termos "estudo sistemático", "desenvolvimento" e "intervenções" como ações e, como objetos, "programas", "estratégias", "materiais", "produtos" e "sistemas". Assim, a DBR é caracterizada como uma abordagem intervencionista, iterativa, orientada por processo, orientada pela utilidade e orientada pela teoria (VAN DEN AKKER et al., 2006, p. 5).

O que contribui para sua confiabilidade, em termos de pesquisa científica, é, mais fortemente, o fato de ela ser iterativa e orientada pela teoria. Isso porque a cada iteração - aplicação do 
artefato pedagógico criado - são coletados dados, e a cada decisão a teoria é consultada. Outra característica que contribui para a confiabilidade da $D B R$ é o fato de ela ser realizada por um grupo de pesquisadores, o que permite criar instrumentos de avaliação mais impessoais em relação ao pesquisador. Por exemplo: quando um professor faz um estudo de caso e analisa a própria disciplina, pode ter seu julgamento comprometido por conta de estar intensamente envolvido com a elaboração e a aplicação dos instrumentos de avaliação, bem como com a análise dos dados resultantes. Na $D B R$, considerando um coletivo de pesquisadores, os dados podem ser tratados de forma mais isenta.

É interessante observar que a $D B R$ se originou e ainda está bastante ligada às pesquisas nas áreas das ciências exatas, da computação e das engenharias, porém, não se restringe a elas. Assim, por a $D B R$ enfocar-se no projeto e na avaliação de uma grande gama de inovações projetadas, incluindo artefatos mais ou menos concretos, assim como estruturas de atividades, instituições, apoios e currículos (DESIGN-BASED RESEARCH COLLECTIVE, 2003, p. 5), é bastante claro que ela pode ser utilizada em todas as áreas, incluindo a da pesquisa no ensino da música. Existem

quatro áreas em que os métodos da design-based research são mais promissores:

(a) explorando as possibilidades de criar novos ambientes de ensino e aprendizagem, (b) desenvolvendo teorias de aprendizagem e instrução que são contextualmente baseadas, (c) avançando e consolidando o conhecimento do design ${ }^{4}$, e (d) ampliando nossa capacidade para a inovação educacional (DESIGN-BASED RESEARCH COLLECTIVE, 2003, p. 6, tradução nossa).

No trabalho maior do grupo, nota-se que todas essas áreas citadas podem ser beneficiadas no ensino da música e em sua pesquisa.

Para se entender melhor a abordagem, serão expostas suas características, conforme o DesignBased Research Collective (2003, p. 5). O coletivo propõe cinco características para a DBR:

\footnotetext{
${ }^{4}$ Observa-se que no presente projeto algumas vezes o termo design, em inglês, é traduzido como projeto e em outras vezes é mantido. Isso é proposital. O termo é mantido em inglês quando se refere mais a princípios ou elementos do projeto.
} 
a. Os objetivos centrais do projeto de ambientes de aprendizagem e o desenvolvimento de teorias ou "proto-teorias" de aprendizagem são interligados.

b. O projeto e a pesquisa ocorrem através de ciclos contínuos de design, aplicação, análise e redesign.

c. A pesquisa em projetos deve gerar teorias compartilháveis que ajudem a comunicar implicações relevantes para profissionais e outros projetistas educacionais.

d. A pesquisa deve explicar como os projetos funcionam em ambientes reais. Ela não deve ser somente uma documentação, do que deu certo ou do que deu errado, e, sim, enfocar as interações que refinam nosso conhecimento das questões de aprendizagem envolvidas.

e. O desenvolvimento destas explicações dependem dos métodos que documentam e conectam os processos de aplicação com os resultados de interesse.

A Figura 1 ilustra o modelo de Thomas C. Reeves, bastante difundido na literatura para a abordagem. A análise dessa figura permite uma grande compreensão do funcionamento da $D B R$. Vê-se quatro fases. Na primeira delas, ocorre a análise de problemas práticos por pesquisadores e profissionais ${ }^{5}$, em colaboração. Na segunda fase, ocorre o desenvolvimento de soluções embasadas nos princípios de design e de inovações tecnológicas. É aqui que o artefato pedagógico é criado. A cientificidade nessas primeiras fases é baseada na teoria e revisões bibliográficas e em levantamentos de dados do contexto e dos usuários.

${ }^{5} \mathrm{O}$ termo traduzido aqui como profissionais, no inglês, é practitioners, que Matta et al. traduziram como "sujeitos engajados na práxis" (MATTA et al., 2014, p. 30). 
Figura 1 - Modelo da $D B R$ de Reeves

Design-Based Research

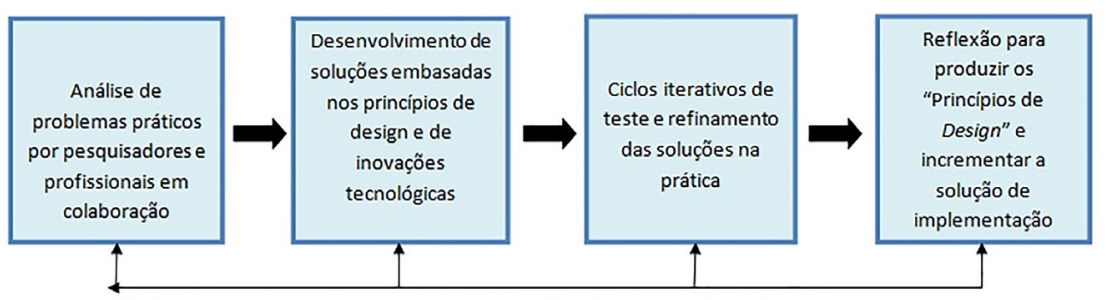

Refinamento dos Problemas, Soluções, Métodos e Princípios de Design

Fonte: VAN DEN AKKER et al., 2006, p. 59, tradução nossa.

Em seguida, ocorre a terceira fase que é a mais longa delas, pois na verdade é baseada em diversos ciclos iterativos de teste e refinamento das soluções na prática. É nessa fase que a maioria dos dados são coletados de modo a fundamentarem as definições dos princípios de design finais que são, de fato, a quarta fase. Após a fase 4, na Figura 1, há uma seta embaixo que indica que mesmo após alguns anos de implementação a $D B R$ pode ser reaplicada de forma iterativa em prol do refinamento dos problemas, soluções, métodos e princípios de design. Esse novo ciclo geral da $D B R$ pode ser realizado pelo mesmo grupo de pesquisadores ou por outros pesquisadores no futuro e em outro contexto.

A Figura 2, por sua vez, apresenta outros aspectos da abordagem. Ela mostra como a DBR se relaciona à ideia de espiral com ciclos das atividades, fases e avaliações de participantes da $D B R$. Essa figura foi concebida para ilustrar uma aplicação da $D B R$ em um projeto de doutorado e representa a pesquisa da pesquisadora, porém, foram realizadas algumas pequenas alterações no texto, de modo a ilustrar uma $D B R$ genérica. 
Figura 2 - Espiral com ciclos das atividades, fases e avaliações de participantes da DBR

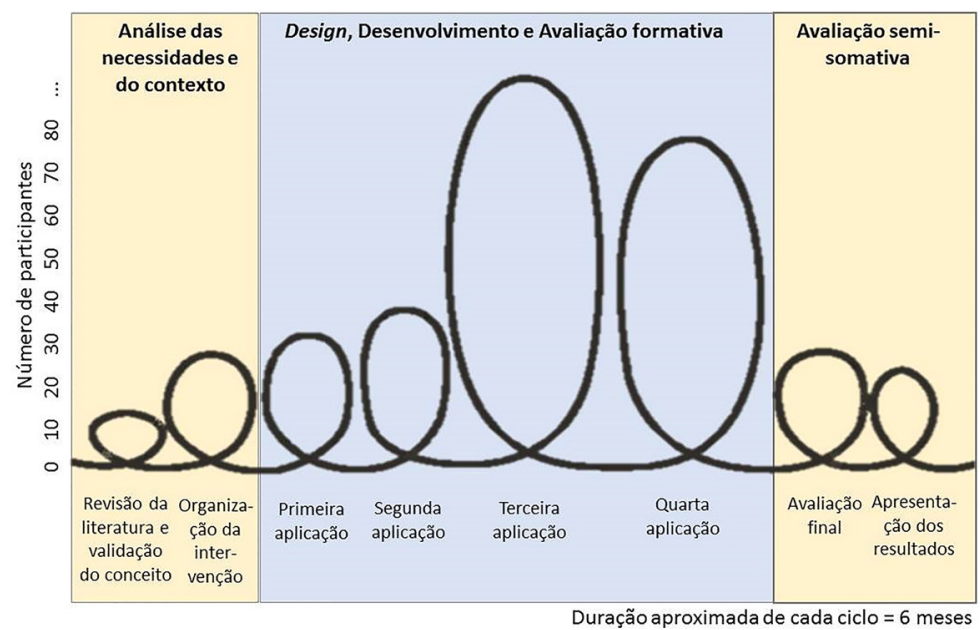

Fonte: adaptado de McKenney, 2001, p. 55.

Na Figura 2, a linha espiralada representa a noção de processo subdividido em especificidades procedimentais da pesquisa. As duas primeiras, da esquerda para a direita, representam as duas primeiras fases da $D B R$. Observa-se que o número de participantes envolvidos é pequeno, se delimitando aos pesquisadores e profissionais envolvidos no planejamento. No recorte central da figura temos a terceira fase da pesquisa com diversas fases de aplicação. Observase que aqui o número de participantes é bem maior, pois refere-se aos estudantes que são submetidos às aplicações. Verifica-se que a cada ciclo a amostra de usuários é diferenciada, possibilitando diversos níveis de avaliação e de validação dos princípios de design que estão sendo estabelecidos. Os dois últimos ciclos da figura representam a última fase da $D B R$, na qual ocorre a avaliação final e a apresentação dos princípios de design. A figura também deixa claro que a abordagem demanda um razoável tempo para a realização, pois cada ciclo pode durar alguns meses, resultando em vários anos para a pesquisa ser finalizada.

Inicialmente é importante salientar que, nesse momento, o grupo de pesquisa em música está na fase 1 da $D B R$ que, segundo Matta et al., se configura conforme o Quadro 1, a seguir. 
Quadro 1 - Elementos da fase 1 da $D B R$

\begin{tabular}{|c|c|c|}
\hline Fase da $D B R$ & Tópicos & Posição da proposta \\
\hline \multirow{4}{*}{$\begin{array}{l}\text { Fase 1: Análise do proble- } \\
\text { ma por investigadores, } \\
\text { usuários e/ou demais } \\
\text { sujeitos envolvidos em } \\
\text { colaboração }\end{array}$} & Definição do problema & \\
\hline & $\begin{array}{l}\text { Consulta recíproca entre } \\
\text { sujeitos engajados na práxis e } \\
\text { investigadores. }\end{array}$ & $\begin{array}{l}\text { Definição do Problema, ou Introdução, } \\
\text { ou Fundamentação, ou Contexto. }\end{array}$ \\
\hline & Questões de pesquisa & Questões de pesquisa \\
\hline & $\begin{array}{l}\text { Contextualização e/ou revisão } \\
\text { de literatura }\end{array}$ & Contexto, ou Revisão de Literatura \\
\hline
\end{tabular}

Fonte: MATTA et al., 2014, p. 30.

Para os autores, na fase 1, "o problema é prioritariamente pensado em termos de uma solução aplicada a uma dada necessidade de práxis de processo de construção de conhecimento" (MATTA et al., p. 29). Nesse sentido, o grupo de pesquisadores da área de música, em associação com pesquisadores da área de educação, considerou que a aprendizagem dos estudantes era um elemento fundamental para ser trabalhado, principalmente no que se relaciona a disciplinas com execução musical e também considerando que o corpo docente é muito pequeno para a demanda de trabalho existente. É importante observar, porém, que, por tratar-se de uma pesquisa científica, o tema deve possibilitar a aplicação de princípios científicos. Segundo Shavelson existem seis princípios de investigação, inter-relacionados, nos quais se baseia a pesquisa científica, em geral:

\footnotetext{
-Colocar questões significativas que possam ser investigadas empiricamente.

-Vincular a pesquisa à teoria relevante.

-Usar métodos que permitam a investigação direta da questão.

-Fornecer uma cadeia de raciocínio coerente e explícita.

-Replicar e generalizar os estudos.

-Divulgar a pesquisa para encorajar o escrutínio e a crítica profissionais. (SHAVELSON; TOWNE, 2002, p. 52, tradução nossa).
}

Então, para garantir a fundamentação científica da DBR, deve-se sempre buscar observar esses aspectos em cada uma das fases. Quando pesquisadores são negligentes com alguns desses itens, geralmente a $D B R$ não resulta em possibilidades de replicação e generalização. Nesse sentido, é fundamental, no início da $D B R$, atentar para a questão de pesquisa a que ela se propõe. Para os autores citados anteriormente, em uma pesquisa 
[...] as perguntas são colocadas em um esforço para preencher uma lacuna no conhecimento existente ou para procurar novos conhecimentos, para buscar a identificação da(s) causa(s) de algum fenômenos, para descrever fenômenos, para resolver um problema prático, ou para testar formalmente uma hipótese (SHAVELSON; TOWNE, 2002, p. 55, tradução nossa).

E, segundo Plomp e Nieveen (2007), ao final da $D B R$ o resultado da pesquisa será algo com a seguinte estrutura de enunciado: "Dado meu contexto, se eu faço <intervenção (baseada na teoria) > então eu espero <resultados pretendidos>" (PLOMP; NIEVEEN, 2007, p. 18, tradução nossa).

Nesse sentido, a questão de pesquisa pode ser estruturada da seguinte forma: "Quais são as características de um(a) <intervenção $X>$ para o propósito/resultado $Y\left(Y_{1^{\prime}}, Y_{z^{\prime}} \ldots, Y_{n^{\prime}}\right.$ ) em um contexto Z" (PLOMP; NIEVEEN, 2007, p. 19, tradução nossa).

Assim, de acordo com esses modelos, a pesquisa geral com a $D B R$ que o grupo de pesquisa em música realizará nos próximos anos, buscará um resultado com a seguinte estrutura: dada uma disciplina de execução musical em um curso superior de música, se eu faço um sistema de avaliação por pares com tais características então eu espero o aprimoramento da aprendizagem do estudante e da satisfação docente.

$\mathrm{E}$, como questão de pesquisa, tem-se: quais são as características de um sistema de avaliação por pares para gerar aprendizagem dos estudantes e satisfação dos docentes em disciplinas de execução musical em cursos de graduação em música?

\section{A AVALIAÇÃO DA EXECUÇÃO MUSICAL EM CURSOS DE GRADUAÇÃO}

Atualmente os processos de avaliação têm sido analisados de forma mais ampla com vistas a considerar sua influência em outros aspectos educacionais. Para corroborar esta indicação pode-se considerar o Assessment 2020, um fórum do Australian Learning \& Teaching Council, que apontou sete princípios para que a avaliação tenha um efeito mais efetivo no aprendizado. Desses princípios, três (1, 3 e 5 ) chamam interesse especial neste projeto. O primeiro preconiza que a avaliação deve ser utilizada para envolver os estudantes em uma aprendizagem produtiva. Sendo assim, a avaliação é tida como uma atividade pedagógica e que requer engajamento e uma preparação adequada. O terceiro princípio diz que os estudantes e os 
docentes são parceiros tanto na aprendizagem quando na avaliação. Por fim, para o quinto princípio, a avaliação deve ser colocada como elemento central do planejamento pedagógico e ser reconhecida como parte do planejamento curricular, $a b$ ovo.

Em um texto atual (de 2015) Katie Zhukov esclarece que

[...] ao longo dos últimos 15 anos, pesquisas documentaram muitas estratégias de avaliação para o ensino superior. Na música, a ênfase tem sido no desenvolvimento de medidas de avaliação confiáveis para execução instrumental e em rubricas multidimensionais para exames práticos (ZHUKOV, 2015, p. 55, tradução nossa).

Dessa forma, na área de música, ao falar-se em avaliação tem-se ainda um diferencial que é a questão da performance, ou execução. Ou seja, é diferente avaliar uma prova escrita de avaliar uma execução musical. Segundo McPherson e Thompson "a avaliação da execução musical é comum entre muitos tipos de prática de educação musical, mas, é relativamente escassa a investigação que clarifique a gama de fatores que afetam a avaliação de um avaliador" (MCPHERSON; THOMPSON, 1998, p. 12, tradução nossa).

Em termos conceituais:

Avaliação da performance musical é o processo em que um indivíduo tenta balancear e sintetizar as várias qualidades da performance de outro indivíduo, com o objetivo de fornecer um julgamento, tal como uma classificação, nota ou descrição qualitativa (MCPHERSON; THOMPSON, 1998, p. 12, tradução nossa).

Os autores também apresentam um modelo de processo de avaliação de execução musical, conforme a Figura 3.

Na Figura 3 é possível observar quão complexo é esse processo de avaliação e que possui um grande potencial para a realização de pesquisas. Porém, o recorte utilizado foi a avaliação por pares. Isso considerando que:

As discussões recentes sobre a avaliação formativa na música têm enfocado nos benefícios potenciais de aprendizagem das rubricas, autorreflexão, autoavaliação e avaliação por pares, como estratégias práticas para promover a aprendizagem através da avaliação (VALLE et al., 2016, p. 41, tradução nossa). 
Nesse mesmo sentido, Zhukov (2015) também argumenta que dentre os estudos de avaliação musical no ensino superior são poucos os que adotam abordagens inovadoras como a avaliação por pares, dentre outras.

Figura 3 - Modelo de processo de avaliação de execução musical

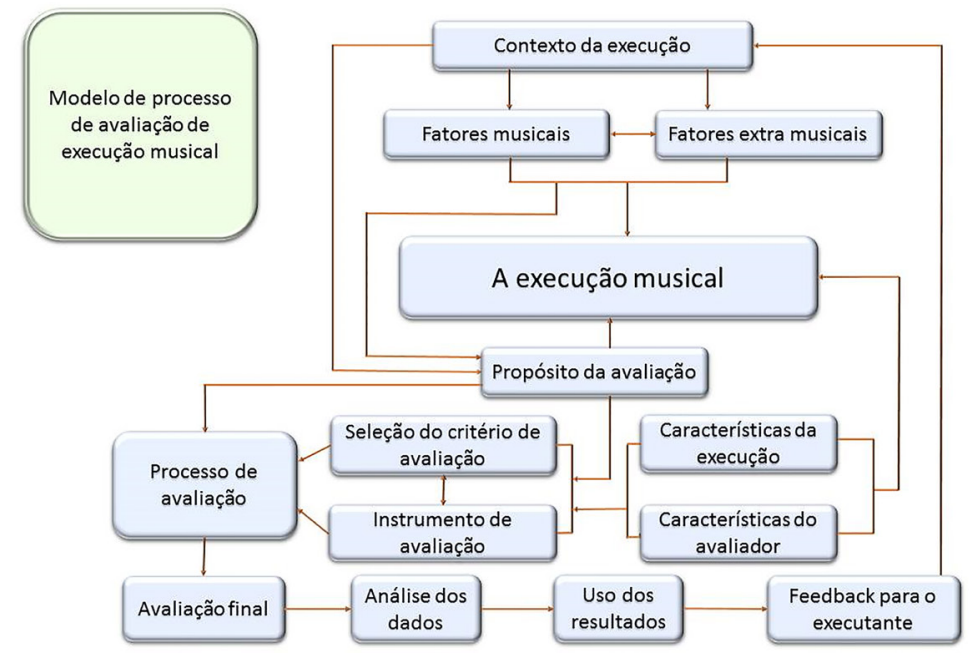

Fonte: MCPHERSON; THOMPSON, 1998, p. 13, tradução nossa.

Segundo relatos como os de Searby e Ewers (1997), a avaliação por pares na música geralmente é pensada como uma maneira de otimizar o trabalho do professor, fazendo com que os próprios estudantes retirem alguma carga do trabalho docente. Porém, na prática isso não ocorre. Mas, por outro lado, a avaliação por pares resulta em um grande aprimoramento pedagógico e de aprendizado dos estudantes.

Topping, em 1998, realizou um levantamento das publicações e utilizações da avaliação por pares no ensino superior e elaborou o seguinte quadro (QUADRO 2). 
Quadro 2 - Uma tipologia da avaliação por pares na educação superior

\begin{tabular}{|c|c|c|}
\hline & Variável & Gama de variação \\
\hline 1 & Assuntos/área do currículo & Todas \\
\hline 2 & Objetivos & $\begin{array}{l}\text { Dos professores e/ou estudante? } \\
\text { Economia de tempo ou ganhos cognitivos/afetivos? }\end{array}$ \\
\hline 3 & Foco & Qualitativa/somativa, qualitativa/formativa ou ambas? \\
\hline 4 & Produtos/resultados & $\begin{array}{l}\text { Testes/marcas/notas, apresentações orais ou escritas, } \\
\text { ou outros comportamentos qualificados? }\end{array}$ \\
\hline 5 & $\begin{array}{l}\text { Relação com a avaliação feita pelo } \\
\text { docente }\end{array}$ & Substitucional ou suplementar? \\
\hline 6 & Peso oficial & Contribui ou não para a média final oficial? \\
\hline 7 & Direcionalidade & É de uma via, recíproca, mútua? \\
\hline 8 & Privacidade & Anônima/confidencial/pública? \\
\hline 9 & Contato & A distância ou presencial \\
\hline 10 & Ano & No mesmo ano ou entre anos de estudo? \\
\hline 11 & Habilidade & A mesma ou entre diferentes habilidades? \\
\hline 12 & Configuração de assessores & Individual, em duplas ou em grupos? \\
\hline 13 & Configuração de assessorados & Individual, em duplas ou em grupos? \\
\hline 14 & Lugar & Dentro/fora da sala de aula? \\
\hline 15 & Tempo & No horário da aula/tempo livre/informalmente? \\
\hline 16 & Exigência & Compulsória ou voluntária para o(s) avaliador(es)? \\
\hline 17 & Recompensa & $\begin{array}{l}\text { Créditos no curso, outros incentivos ou reforço para a } \\
\text { participação? }\end{array}$ \\
\hline
\end{tabular}

Fonte: TOPPING, 1998, p. 251-251, tradução nossa.

Especificamente, no que tange à avaliação por pares na música, um artigo é seminal: "An evaluation of the use of peer assessment in higher education: a case study in the School of Music", de Mike Searby e Tim Ewers, que apresenta um estudo de caso no qual foi implantada a avaliação por pares em um curso superior de música, entre os anos de 1992 e 1995, e traz muitas contribuições para a área. Porém, outros estudos também são bastante esclarecedores, como "Peer assessment in performance studies", de Desmond Hunter e Michael Russ (1996), e o livro Music Psycology in Education, de Susan Hallam (2006), que apresenta uma interessante contextualização da avaliação em geral e da avaliação por pares na aprendizagem musical. 
É interessante observar que, embora já há algumas décadas a avaliação por pares em música seja discutida ao redor do mundo, pouca literatura nacional, ou mesmo lusófona, seja encontrada. Por exemplo, em pesquisa recente na principal revista da área de educação musical no Brasil, a revista da Associação Brasileira de Educação Musical, o termo "avaliação" só resulta em 21 artigos, nenhum deles se referindo à avaliação por pares no ensino ${ }^{6}$.

Considerando tudo o que foi exposto anteriormente, os grupos de pesquisadores da área da música e da área da educação justificam o projeto de pesquisa conforme os seguintes itens:

- Necessidade de estudos lusófonos sobre avaliação por pares no ensino da música.

- Necessidade de estudos regionais ou locais sobre a avaliação por pares para aplicação direta com o grupo engajado na práxis.

- Importância da integração de diversos projetos de pesquisa alinhados para fortalecer a área de pesquisa de maneira mais eficiente na UFSCar.

\section{DINÂMICA DE TRABALHO E RESULTADOS ATÉ O MOMENTO}

A quantidade de participantes em uma $D B R$ pode variar bastante de fase para fase, como foi comentado anteriormente. Nesta primeira fase existem cerca de sete pesquisadores diretamente envolvidos e alguns outros colaboradores que são sujeitos engajados na práxis, ou seja, outros docentes do ensino superior de diversas universidades, prioritariamente envolvidos com cursos de graduação em música.

As reuniões, indispensáveis na $D B R$, estão sendo viabilizadas por encontros presenciais e centralizadas em um ambiente virtual criado para a pesquisa. Nesses espaços os pesquisadores organizam os subprojetos e o projeto geral, elaboram publicações colaborativamente, aprendem sobre a abordagem e realizam cada uma das fases da $D B R$ geral. Essa organização é fundamental para poder-se lidar adequadamente com a quantidade de dados que a abordagem gera.

Para a viabilização das primeiras fases da $D B R$, as seguintes pesquisas subsidiárias estão sendo concebidas:

${ }^{6}$ Aliás, na literatura nacional o termo "avaliação por pares" aparece muito em instruções sobre avaliação de artigos para revistas. 
1. Percepção de docentes sobre a avaliação por pares em atividades musicais no ensino superior.

2. Construção colaborativa de critérios de avaliação da execução musical por pares num grupo de performance musical com flauta doce.

3. $D B R$ na adaptação de games musicais.

4. Modelos de processos de avaliação de execução musical no ensino superior.

5. Ferramentas computacionais de apoio para a avaliação por pares.

6. Ensino homogêneo e heterogêneo de instrumentos musicais no ensino superior.

7. Gravações de áudio e vídeo no apoio à avaliação por pares no ensino superior de música.

Como foi exposto anteriormente, a $D B R$ necessita ser subsidiada por metodologias de pesquisa diversas em cada uma de suas fases, para alcançar resultados científicos generalizáveis e embasados. Assim, cada uma dessas sete pesquisas subsidiárias, em geral, utiliza os seguintes elementos:

- Objetivos gerais e específicos que se comunicam com a pesquisa maior.

- Plano de trabalho: envio do projeto para aprovação no Comitê de Ética em Pesquisa; elaboração de listas de palavras e autores chave; busca por fontes de material; leitura prévia para seleção dos textos; elaboração de fichamentos dos textos-chave; elaboração de um quadro para estruturação da revisão bibliográfica com questões guia, citações diretas, citações indiretas, dados e estatísticas e comentários; redação de um texto final sobre a literatura abordada; revisão bibliográfica sobre metodologia de pesquisa; definição da população e da amostra; elaboração do instrumento de coleta de dados; aplicação do instrumento de coleta de dados; análise dos dados; elaboração do relatório de pesquisa final; e divulgação em congressos, revistas etc.

As pesquisas, em geral, são do tipo exploratória que, segundo Diehl e Tatim (2004, p. 53), "têm como objetivo proporcionar maior familiaridade com o problema, com vistas a torná-lo mais explícito ou a construir hipóteses". Embora muitos elementos da abordagem quantitativa venham a ser utilizados, segundo a natureza do problema, a pesquisa é enquadrada como qualitativa (devido à amostragem, a alguns tipos de questões a serem exploradas no 
instrumento e ao tratamento dos dados ${ }^{7}$ ). Segundo o procedimento técnico, as pesquisas iniciam uma revisão bibliográfica e depois disso foca-se em um levantamento sobre os aspectos a serem abordados. Para tal, são elaborados formulários eletrônicos (survey) nos quais os sujeitos expressam a opinião sobre diversos fatores.

Em seguida, os resultados são analisados conforme os procedimentos indicados a seguir:

- Seleção: são selecionados apenas os questionários que respeitem alguns critérios mínimos a serem definidos, por exemplo, ser professor no ensino superior de música.

- Classificação: Cada questão respondida é transposta em planilha eletrônica. Assim os dados podem ser filtrados conforme os critérios a serem definidos no âmbito da pesquisa.

- Codificação: o modelo de codificação é simples, uma vez que a maioria das questões é fechada. Todavia, se necessário, pode ser utilizada alguma diretriz adicional, ou matriz, para organizar melhor as respostas em algumas questões que eventualmente forem abertas.

- Representação: em via de facilitar a visualização das informações coletadas, são gerados gráficos por meio dos dados na planilha eletrônica, bem como são elaborados quadros ou tabelas.

- Análise: são realizadas análises uni e bivariadas.

A expectativa é que, ao final desta pesquisa, que demandará de três a quatro anos, muitos princípios de design tenham sido propostos e testados e que diversas contribuições teóricas possam ter sido realizadas para a área de música e educação no ensino superior, tanto no que se refere ao uso da abordagem da $D B R$, quanto na sistemática de trabalhos colaborativos de pesquisa, na avaliação por pares e na avaliação musical.

\footnotetext{
${ }^{7}$ Para Mascarenhas (2012) "a pesquisa quantitativa baseia-se na quantificação para coletar e, mais tarde, tratar os dados obtidos" (p. 45). E segundo Cohen et al. (2007, p. 501) a "análise quantitativa dos dados é uma forma de pesquisa poderosa, que emana em parte da tradição positivista. Ela é frequentemente associada com a investigação em grande escala, mas também pode servir investigações de menor escala, com estudos de caso, pesquisa-ação, pesquisa correlacional e experimentos".

Mascarenhas (2012) argumenta que "utilizamos a pesquisa qualitativa quando queremos descrever nosso objeto de estudo com mais profundidade. Por isso, ela é muito comum em estudos sobre o comportamento de um indivíduo ou de um grupo social" (p. 46).
} 


\section{CONSIDERAÇÕES FINAIS}

Ao final deste artigo pode-se destacar alguns elementos-chave até o momento observados pelos grupos de pesquisa em música e educação envolvidos no projeto. A primeira consideração é que a $D B R$ tem se mostrado altamente eficaz no alinhamento de pesquisas realizadas por um ou mais grupos de pesquisa. Esse alinhamento possibilita que haja uma maior colaboração entre os pesquisadores e também que as pesquisas sejam, cientificamente, mais robustas, pois um projeto é analisado e observado por um grande número de pesquisadores. A segunda consideração é que a avaliação por pares tem sido muito pouco pesquisada no Brasil e, em se referindo ao ensino superior em música, menos ainda. Tal lacuna deve ser sanada uma vez que a avaliação por pares tem um grande potencial no ensino superior, conforme as experiências estrangeiras têm apontado. Por fim, com esta experiência, os pesquisadores dos dois grupos de pesquisa envolvidos têm aprendido a realizar sua pesquisa com o auxílio de ambientes virtuais que facilitam a organização dos dados e das ações referentes às pesquisas.

\section{REFERÊNCIAS}

BOUD, D. \& Associates. Assessment 2020: seven propositions for assessment reform in higher education. Sydney, Australia: Australian Learning and Teaching Council, 2010.

COHEN, Louis; MANION, Lawrence; MORRISON, Keith. Research methods in education. London: Routledge, 2007. 638 p.

DESIGN-BASED RESEARCH COLLECTIVE. Design-Based Research: an emerging paradigm for educational inquiry. In: Educational Researcher, Washington, v. 32, n. 1, p. 5-8, 2003.

DIEHL, Astor; TATIM, Denise Carvalho. Pesquisa em ciências sociais aplicadas: métodos e técnicas. São Paulo: Prentice Hall, 2004.

HALLAM, Susan. Music psychology in education. London: Bedford Way Papers (Institute of Education, University of London), 2006. 281 p.

HUNTER, D.; RUSS, M. Peer assessment in performance studies. In: British Journal of Music Education, Cambridge, v. 13, n. 1, p. 67-78. 1996.

MASCARENHAS, Sidinei Augusto. Metodologia científica. São Paulo: Pearson Education do Brasil, 2012. 126 p. 
MATTA, Alfredo Eurico Rodrigues; SILVA, Francisca de Paula Santos da Silva; BOAVENTURA, Edvaldo Machado. Design-Based Research ou pesquisa de desenvolvimento: metodologia para pesquisa aplicada de inovação em educação do século XXI. In: Revista da FAEEBA Educação e Contemporaneidade, Salvador, v. 23, n. 42, p. 23-36, jul./dez. 2014.

MCKENNEY, Susan. Computer-based support for science education materials developers in Africa: exploring potentials. Doctoral dissertation. Enschede: University of Twente, 2001. $281 \mathrm{p}$.

MCNEILL, Patrick; CHAPMAN, Steve. Reserarch methods. London: Routledge, 2005. 214 p.

MCPHERSON, Gary E.; THOMPSON, William F. Assessing music performance: issues and incluences. Research Studies in Music Education, Sydney, n. 10, p. 12-24. jun. 1998.

PLOMP, Tjeerd; NIEVEEN, Nienke (Ed.). An introduction to educational design research. Uitgever: SLO, Enschede, 2009. 126 p.

SEARBY, Mike; EWERS, Tim. An evaluation of the use of peer assessment in higher education: a case study in the School of Music, Kingston University. Assessment \& Evaluation in Higher Education, v. 22, n. 4, p. 371-383, 1997.

SHAVELSON, R.; TOWNE, L. Scientific research in education. Washington DC: National Academic Press, 2002. 188 p.

TOPPING, Keith. Peer assessment between students in colleges and universities. Review of educational research, v. 68, n. 3, p. 249-276, Fall, 1998.

VALLE, Christopher; ANDRADE, Heidi; PALMA, Maria; HEFFEREN, Joanna. Applications of peer assessment and self-assessment in music. Music Educators Journal, v. 102, n. 4, p. 41-49, jun. 2016.

VAN DEN AKKER, J.; GRAVEMEIJER, K; MCKENNEY, S.; NIEVEEN, N. (Ed.). Educational design research. London: Routledge, 2006. 163 p.

ZHUKOV, Katie. Challenging approaches to assessment of instrumental learning. In: LEBLER, Don; CAREY, Gemma; HARRISON, Scott D. (Ed.). Assessment in music education: from policy to practice. Springer/Cham/Heidelberg/New York/Dordrecht/London: Springer International Publishing Switzerland, 2015. p. 55-70. 


\section{Daniel Mill}

Professor associado da UFSCar. Docente e Gestor de Educação a Distância. Membro dos Programas de Pós-Graduação em Educação e em Ciência, Tecnologia e Sociedade. Líder do Grupo Horizonte (Grupo de Estudos e Pesquisas sobre Inovação em Educação, Tecnologias e Linguagens), com interesse na interseção das temáticas: trabalho docente, tecnologias, linguagens, cognição, educação a distância, gestão e políticas públicas.

mill.ufscar@gmail.com

\section{Glauber Lúcio Alves Santiago}

Professor associado da UFSCar na área da música. Arranjador, compositor e produtor musical. Tem pesquisado sobre educação musical, tecnologias e EaD. É líder do grupo de pesquisa Tecnologias Aplicadas ao Ensino e Aprendizagem Musical. Atualmente também é coordenador da Coordenadoria de Inovações em Tecnologias na Educação da Secretaria Geral de Educação a Distância da UFSCar.

glauber@ufscar.br

\section{José Alessandro Gonçalves da Silva}

Docente efetivo no Departamento de Artes e Comunicação da UFSCar. Tem experiência na área de Artes, com ênfase em Instrumentação Musical, atuando principalmente nos seguintes temas: performance, clarineta, sax, orquestra, música, educação musical, ensino coletivo de sopros e EaD/UAB/UFSCar. Atualmente é coordenador do Curso Presencial de Licenciatura em Música.

alessandro30silva@gmail.com

\section{Isamara Alves Carvalho}

Doutora em Educação pela UFSCar. Professora efetiva no Departamento de Artes e Comunicação da UFSCar, atuando nos cursos de graduação em Música (presencial) e em Educação Musical (a distância), do qual foi coordenadora no período de dezembro de 2011 a dezembro de 2015. Atualmente pesquisa nas áreas de educação musical, ensino de instrumento e uso de recursos tecnológicos musicais.

profa.isamara@gmail.com 